\title{
Avaliação da evasão do curso de licenciatura em ciências agrárias da Unidade Universitária da Uergs em Vacaria (RS)
}

\author{
Carina Barboza Pegoraro', Guilherme Kunde Braunstein² \\ ' Licenciada em Ciências Agrárias. Universidade Estadual do Rio Grande do Sul (Uergs). \\ E-mail: carinabarbozapegoraro@gmail.com \\ 2 Mestre em Educação em Ciências. Professor assistente da Universidade Estadual do Rio Grande do Sul (UERGS). \\ E-mail: guilherme-braunstein@uergs.edu.br
}

\section{Resumo}

As taxas de desistências no ensino superior variam de acordo com a área de conhecimento, região, perspectivas de mercado, tipos de processos seletivos, problemas financeiros e formação sólida durante o ensino médio. Devido ao alto percentual de evasão verificado na Licenciatura em Ciências Agrária da Uergs-Vacaria, esse trabalho teve como objetivo verificar os motivos que elevaram a evasão a taxa de $71 \%$ no ano de 2019 . A metodologia para a criação deste trabaIho se deu através da interação da pesquisa documental e de campo. A pesquisa documental foi realizada em artigos, materiais de congressos, seminários, revistas, sites e plataformas idôneas. Para a pesquisa de campo foram realizadas entrevistas com perguntas abertas, de forma individual e gravadas a fim de registrar a opinião dos professores e universitários que continuam e aqueles que evadiram do curso sobre possíveis causas para a evasão. Os motivos relatados nas entrevistas foram diversos, entre os mais mencionados estão a falta de reconhecimento do curso, de divulgação e afinidade com o curso e falta de interesse da instituição e dos professores com mesmo. Deste modo, faz-se necessário um planejamento eficaz, para a abertura de novos cursos para que os mesmos sejam de qualidade e satisfaçam todos os envolvidos (alunos, professores e funcionários) de forma a minimizar a evasão.

Palavras-chave: Evasão. Ciências agrárias. Licenciatura. Desmotivação.

\section{Abstract}

\section{Evaluation of the evasion in the agricultural science degree in Vacaria (RS) Uergs University Unit}

The dropouts rates in higher education vary according to the knowledge area, region, market prospects, types of selection processes, financial problems, and solid education during high school. Due to the high dropout rate in the Degree in Agrarian Sciences at Uergs-Vacaria, this work aims to verify the reasons that raised this rate to $71 \%$ in 2019. The methodology for the creation of this work was through the interaction of documentary and field research. The documentary research was conducted in articles, congress materials, seminars, magazines, websites and suitable platforms. For the field research, interviews were conducted with open questions were conducted, individually and recorded in order record the opinion of teachers and university students who continue and those who dropped the course on possible causes for dropout. The reasons reported in the interviews were diverse, among the most mentioned are the lack of recognition of the course, disclosure and affinity with the course and lack of interest of the institution and the teachers with it. Thus, it is necessary to have an effective planning, for the opening of new courses so that they are of quality and satisfy all involved (students, teachers and employees) in order to minimize evasion.

Keywords: Evasion. Agricultural sciences. Degree in education. Demotivation. 


\section{Introdução}

O aumento de desistências no ensino superior é uma preocupação constante de pesquisadores e autoridades (LOBO, 20I2). Sendo os motivos prováveis para a evasão os mais variados possíveis incluindo falta de tempo, necessidades econômicas, falta de motivação ou perspectiva de mercado, problemas financeiros e formação sólida no ensino médio (ASSIS, 20I3).

No que diz respeito a evasão no ensino superior, segundo o Ministério da Educação (MEC) as universidades brasileiras apresentam um elevado índice de evasão, o que demonstra a fragilidade do ensino médio no país, nesse sentido os dados apresentados pela Censo da Educação Superior revelariam um aumento na evasão dos egressos ao longo de suas trajetórias entre 2010 e 20I4, de modo que já em 2010 a porcentagem de estudantes recém-ingressantes na universidade que já haviam abandonado o curso para o qual foram admitidos chegava a II,4\%, enquanto que em 2014 esse número já atingia 49\% (MEC, 20I6). Conforme dados do INEP, no ano de 2007 as licenciaturas obtiveram os maiores percentuais de evasão, já em 2016 os maiores índices de evasão foram em cursos tecnológicos e em 2017 licenciaturas e bacharelados tiveram um percentual médio de abandono de 39\% (BRASIL, 2017).

Considerando a evasão no contexto de graduações ligadas à área de Ciências Agrárias, Davok e Bernard (2016) apontam que no caso da Universidade do Estado de Santa Catarina (UDESC) os cursos das áreas Pedagogia, Agronomia e Medicina Veterinária apresentam índices de evasão de 12,6\%, 8,5\% e 7,5\% respectivamente. Os cursos da grande área das Ciências Agrárias, apresentaram um índice médio de evasão de 31,5\%.

Em referência a Licenciatura em Ciências Agrárias (LICA) estão registrados no o portal e-MEC 2I cursos no país; duas delas oferecidas na forma de ensino a distância (EAD) e 19 como ensino presencial (cinco em processo de extinção). Desses cursos, 47,37\% estão na região nordeste; $31,58 \%$ na região norte; $15,79 \%$ na região sul e 5,26\% no Sudeste, e atendem demandas especificas de cada região (BRASIL, 20I9).

Com base no acima exposto este trabalho teve o objetivo de analisar os aspectos que influenciaram a evasão dos discentes do curso de Licenciatura em Ciências Agrárias (LICA) na Universidade Estadual do Rio Grande do Sul (UERGS) na unidade universitária em Vacaria, tendo em vista que o índice de evasão chegou a $71 \%$ durante o primeiro semestre de 2019. Além da análise, propomos uma reflexão sobre os prováveis fatores que contribuíram para esse quadro a partir da ótica dos sujeitos envolvidos no cotidiano acadêmico.

\section{História rural/agrária do município de Vacaria (RS)}

A Uergs conta com 23 unidades universitárias com ingresso acadêmico no estado do Rio Grande do Sul, sendo que o curso LICA foi implantado exclusivamente na unidade universitária em Vacaria. A história do município de Vacaria nasce com a pecuária e com a classe social típica que se caracteriza com essa atividade econômica. Desde sua formação inicial, sua evolução é dada pela grande quantidade de gado existente em sua extensão, tendo esta característica caráter decisivo na formação social, política, econômica e urbana da cidade (BORGES, 200I). No início do século XX imigrantes italianos instalaram-se em Vacaria compondo a mão de obra que impulsionou o desenvolvimento e a expansão urbana da cidade. Os italianos também ocuparam pequenas propriedades rurais voltadas à agricultura (MOLINA, 2004). Hoje a produção original de subsistência na cidade tem sido a uva, a maçã, o milho, a soja e o trigo. Sendo que a maior responsável pela importância econômica é a maçã, dado confirmado pelo valor de sua produção e pela extensão da área plantada (MOLINA, 2004).

Visto que a agricultura e a pecuária são de grande importância econômica para o município, é de suma importância que o ensino nessa região seja voltado para a realidade do município. Posicionamento que atende o objetivo principal da Uergs, qual seja:

Art. $2^{\circ}$ - A UERGS tem por objetivo: ministrar o ensino de graduação, de pós-graduação e de formação tecnólogos; oferecer cursos presenciais e não presenciais; promover cursos de extensão universitária; fornecer assessoria científica e tecnológica e desenvolver a pesquisa, as ciências, as letras e as artes, enfatizando os aspectos ligados à formação humanística e à inovação, à transferência e à oferta de tecnologia, visando ao desenvolvimento regional sustentável, o aproveitamento de vocações e de estruturas culturais e produtivas locais (RIO GRANDE DO SUL, 200I). 


\section{Escolas do campo}

A escola é a principal instituição responsável pela apresentação às novas gerações dos conhecimentos acumulados historicamente, tratando-se de um processo de construção de todo o saber socialmente instituído e historicamente acumulado. Neste sentido, significa transmitir-lhes uma das condições da continuidade da produção e reprodução da vida no seu sentido amplo e social (SILVA; MUZARDO, 20I7).

Tomando por base a lei n. 9394/96, Diretrizes e Bases da Educação Nacional, é possível identificar de modo claro o foco que a legislação traz para a valorização dos saberes e características locais ao serem celebradas as relações de ensino e aprendizagem, de tal forma que o ensino de qualidade é por ela entendido como aquele que possa responder às diferentes demandas de cada povo:

Art. 28. Na oferta da educação básica para a população rural, os sistemas de ensino promoverão as adaptações necessárias à sua adequação, às peculiaridades da vida rural e de cada região, especialmente:

Conteúdos curriculares e metodologias apropriadas às reais necessidades e interesses dos alunos da zona rural;

Organização escolar própria, incluindo a adequação do calendário escolar as fases do ciclo agrícola e as condições climáticas;

Adequação à natureza do trabalho na zona rural (BRASIL, 1996, art. 28)

Pensando em escolas do campo se faz necessário contextualizar o público por ela atendido como muitas vezes formado por sujeitos vitimados pela supressão de direitos, o qual é composto por pequenos agricultores, mulheres camponesas, atingidos por barragens, sem-terra e outros grupos que travam uma luta incansável pelas condições de produção da vida no campo, sujeitos esses que tem um papel essencial na manutenção da produtividade da Terra e que historicamente dependem de uma série de programas e políticas governamentais para avançarem academicamente enquanto residem de áreas rurais (VANDRAMINI, 20I5).

Nas escolas do campo os estudantes muitas vezes frequentam classes multisseriadas devido à baixa densidade populacional na zona rural, além disso o baixo número de professores e as dificuldades de locomoção são alguns dos problemas enfrentados pelos estudantes. Isso aliado à baixa qualidade do ensino, problemas de aprendizagem e da repetência geram percentuais de analfabetos superiores a $20 \%$ nas zonas rurais do país (BRASIL, 2007).

Além dos fatores apresentados, outro agravante para a educação do campo é que $89,8 \%$ das escolas com ensino médio está situada na zona urbana, contra apenas $10,2 \%$ situadas nas zonas rurais. Sendo dessa forma a falta de escolas no meio rural o mais importante motivo pelo qual tantos brasileiros apresentem grau de escolaridade de educação básica incompleta (BRASIL, 20I8).

Dessa forma, o ensino nas escolas rurais, caso comum na Região dos Campos de Cima da Serra, deve priorizar metodologias e conhecimentos que tenham conexão com o trabalho no campo, baseando-se em questões de interesse dos campesinos e levando em conta as peculiaridades de suas vidas, tais como o enfoque em questões como a defesa do meio ambiente, tecnologias agrícolas, novos maquinários, exercício político e cidadania (ROTTA; ONOFRE, 2010).

Sendo assim, para que os processos educativos tenham resultados devem ser considerados os fatores econômicos, raciais, culturais, financeiros, religiosos de cada comunidade, pois quando estes fatores são ignorados o processo educativo fica restrito, antiquado e alheio à realidade do aluno, portanto insignificante (ROTTA; ONOFRE, 20I0).

Ao pensar na educação em geral e na educação no campo em específico, considera-se que a relação pedagógica na escola deve buscar a emancipação social, criando condições para a reflexão sobre o papel do conhecimento, possibilitando que o discente desenvolva conhecimentos teóricos e, assim, consiga fazer julgamento e estar preparado para tomar decisões diante das demandas do cotidiano (SILVA, 20I0). Dessa forma, o educador do campo traz consigo a condição de promover mudanças gradativas e significativas para a classe trabalhadora, mas, para isto, sua postura ética tem que convergir com a lógica dos agricultores.

Segundo dados do Programa Nacional de Educação no Campo (PRONACAMPO) 30,9\% dos profissionais que lecionam na zona rural não possuem ensino superior completo (PRONACAMPO, 20I2). Indicando a importância de fortalecer a formação desses profissionais. Entender e compreender a realidade em que vive o trabalhador campesino é o primeiro passo para que o professor consiga trabalhar a grade curricular com conteúdos condizentes com as condições dos trabalhadores rurais, quais sejam: uso e preparo do solo, agroecologia, agricultura familiar, dentre outras voltadas a dinâmica da escola do campo. 
O profissional que atende a educação no campo deve ter uma formação plena para administrar conteúdos obrigatórios da grade curricular integrando-os à realidade de seu público. Incorporando à sua formação princípios agroecológicos e de sustentabilidade e o comprometimento com as questões éticas e socioambientais, bem como aprendizagens de conhecimentos científicos e tecnológicos adequados e adaptados às pequenas propriedades (agricultura familiar) e também para a organização do trabalho agroindustrial, sendo capazes de atuação como empreendedor voltado para uma formação humanista e tecnológica (MORAES, 20I4).

\section{Curso superior de Licenciatura em Ciências Agrárias (LICA)}

A formação do curso de LICA possibilita ao professor ter a qualificação necessária para atender o alunado nas cidades em que a agricultura e a pecuária são a principal economia ou que de algum modo está presente no cotidiano dos mesmos. O curso de Licenciatura em Ciências Agrícolas/Agrárias iniciou em I963, na Escola de Educação Técnica que estava vinculada com Universidade Rural do Brasil, no estado do Rio de Janeiro. A criação do curso visava atender o então Art. 59 da Lei de Diretrizes e Bases da Educação (Lei 4.024/6I), com o objetivo de formar professores que pudessem melhorar a qualidade do ensino no campo. Em 1967, a unidade passou a ser chamada de Universidade Federal Rural do Rio de Janeiro (UFRRJ), de forma que a Licenciatura em Ciências Agrícolas foi o primeiro curso voltado à formação de professores na área de Ciências Agrárias da América Latina e o primeiro curso de licenciatura da UFRRJ (MORAES, 20I4).

Em 197I a Licenciatura em Ciências Agrícolas passou também a fazer parte da Universidade Federal Rural de Pernambuco, que teve como objetivo formar professores agrícolas para as escolas técnicas da região nordeste do Brasil. O curso foi planejado de acordo com a Resolução 09/69 e o parecer II I/7 I do Conselho Federal de Educação (TAVARES, 2005) se espalhando de forma gradativa pelo Brasil.

No final de 2014 a LICA-Uergs foi criado pelo corpo de docente da Uergs e passou a ser ofertado em 2015 com o seguinte objetivo:

Formar professores com sólida concepção pedagógica para atuarem nos espaços educacionais na área de Ciências Agrárias como na Educação Básica, Profissional Técnica de Nível Médio, assim como organizações não governamentais, entre outros. A formação estará pautada em sólidas concepções pedagógicas, políticas, científicas e tecnológicas, com conhecimento da dinâmica da realidade e da educação agrícola, dos sistemas de ensino e da escola enquanto realidades concretas de um contexto histórico-social, capazes de buscar alternativas frente às diferentes situações da prática educativa em suas diversas modalidades, que consigam investigar e produzir conhecimentos sobre o meio ambiente e as finalidades da educação agrícola, bem como sobre os meios apropriados de formação humana. (UERGS, 20I5a).

O processo seletivo para a entrada no curso aconteceu através do Sistema de Seleção Unificada (Sisu) com 40 vagas disponíveis para o curso, ofertadas apenas na unidade de Vacaria. Para participar do Sisu, o candidato utilizou a nota obtida no Exame Nacional do Ensino Médio (Enem) 20I4. No dia 26 de janeiro de 2015 o Ministério da Educação divulgou a relação dos aprovados. A primeira chamada para os candidatos foi realizada dos dias 30 de janeiro à 03 de fevereiro, neste período os interessados comparecerem na unidade da Uergs em Vacaria com os documentos necessários para a realização da matrícula. Quem não foi selecionado na primeira chamada pôde se inscrever na lista de espera. As aulas iniciaram no dia 02 de março de $20 I 5$ para os ingressantes da primeira e segunda chamada do processo seletivo (UERGS, 20I5b). Outras 4 vagas foram preenchidas através do edital $\mathrm{N}^{\circ} 0 \mathrm{I} / 2015$ promulgado pela Uergs e que tomou por base as notas obtidas no Enem 20l4. Os candidatos interessados pelas vagas remanescentes realizaram uma pré-matrícula de forma presencial na unidade com os documentos necessários e iniciaram o curso no dia 03 de março de 2015. A turma iniciou o primeiro semestre com 42 alunos (UERGS, 20I5c).

\section{Metodologia}

Esta pesquisa propôs uma interação entre dados de pesquisa bibliográfica, documental e de campo. A pesquisa documental foi realizada em artigos, materiais de congressos, seminários, revistas, sites e plataformas idôneas. $O$ uso de documentos em pesquisa traz informações que podemos extrair e resgatar, 0 que pode ser utilizado em diversas áreas e assim ampliar o entendimento e facilitar a compreensão (SILVA; ALMEIDA; GUINDANI, 2009).

Pegoraro \& Braunstein | Rev. Elet. Cient. da UERGS (2020) v. 6, n. 01, p. 92-I08 
Para a realização da pesquisa de campo o projeto foi submetido ao Comitê de Ética em Pesquisa da Uergs, tendo sido aprovado quanto aos princípios éticos com o CAAE 04I295 |8.8.0000.8091. Nessa etapa foram utilizadas como instrumentos de coleta de dados entrevistas semiestruturadas, constituídas por perguntas abertas mediante termo de livre esclarecimento, visando que o entrevistado respondesse de forma livre, usando linguagem própria, emitindo opiniões e podendo relatar mais de uma resposta para cada pergunta, possibilitando investigações mais profundas e precisas (MATTOS, 2005). A entrevista é uma das técnicas mais utilizadas em trabalhos científicos, permitindo ao pesquisador extrair uma quantidade muito grande de dados e informações que possibilitam um trabalho bastante rico, chegando a um resultado satisfatório (BRITTO JÚNIOR; FERES, 20I I). Este processo dinâmico de confronto constante entre a pesquisa de campo e a teoria dá base para novas concepções e, por consequência, um novo olhar sobre o objeto e o interesse do investigador (SILVA; ALMEIDA; GUINDANI, 2009). As entrevistas foram realizadas com professores, funcionários, alunos ainda cursantes e alunos evadidos da LICA.

Os entrevistados foram contatados por redes sociais e na própria instituição e as entrevistas foram realizadas de março a abril de 2019, feitas individualmente com cada participante e registradas com a utilização de um gravador de voz. Os roteiros de entrevistas foram aplicados a grupos diferentes: os estudantes que continuam no curso, os evadidos e os funcionários e professores que atuam ou atuaram na LICA. Cada roteiro se constituiu de perguntas abertas, porém, diferentes de acordo com cada grupo. Essa metodologia teve por objetivo permitir a livre resposta dos entrevistados dentro de um tema de interesse em específico (MARCONI; LAKATOS, 20I7).

\section{Resultados e Discussões}

A 9a edição do Mapa do Ensino Superior mostra que a evasão nas universidades do país em 2017 atingiu $28,5 \%$ na rede privada e $18,6 \%$ na rede pública, indicando que, tanto em universidades privadas, quanto em públicas, os índices de evasão variam conforme o curso, a modalidade de ensino e diversos outros fatores ligados a vida do educando (SEMESP, 2019). Dentre as licenciaturas brasileiras em 2014, o nível de evasão do curso de pedagogia chegou a 39\%, já nas licenciaturas de física, química e matemática a evasão chegou a $57,2 \% ; 52,3 \%$ e 52,6\%, respectivamente (BRASIL, 20I7).

Apesar de ser um curso com alta procura no ano de 2015 (254 interessados de todo o Brasil, dados obtidos na secretaria da unidade) e preenchimento de $100 \%$ das vagas, é um curso com alta evasão desde a sua implantação. Entre 2015 e 2017 mais de $60 \%$ dos matriculados já haviam desistido por diferentes motivos, chegando ao índice de $71 \%$ de evasão em 2019.

No que refere ao corpo docente da Uergs a Lei Estadual $n^{\circ} 13.968$, de 12 de abril de 2012 estabelece o número de docentes esperado na Universidade em 600 , porém, em agosto de 2018 estavam registrados 293 docentes, dos quais nove lotados na unidade em Vacaria (UERGS, 2018). Destes, seis eram bacharéis e quatro licenciados. Em 2015 tínhamos cinco bacharéis e um licenciado na unidade, e em 20I7, apenas quatro bacharéis em agronomia e nenhum licenciado, estando a partir desse ano os professores divididos no atendimento da LICA e de turmas de Agronomia (curso em convênio com o IFRS).

O momento de maior evasão aconteceu entre o início e a metade do curso, quando mais de $60 \%$ dos alunos evadiram (contra $11 \%$ de alunos que iniciaram o curso evadidos na última metade do curso, totalizando os 7 I\%). Diversos foram os motivos relatados para esse alto índice de evasão da LICA-Uergs. Para chegar aos motivos da evasão durante o curso foram entrevistados os estudantes ainda matriculados nele, os evadidos e os professores e funcionários.

\section{Alunos matriculados do curso de licenciatura em ciências agrárias}

Os motivos que levaram esses $29 \%$ do total matriculados a continuarem com essa graduação variam entre o desejo de ter uma graduação, o sonho de ser professor, a vontade de melhorar a sua situação financeira e a busca por conhecimento. Oito desses 10 estudantes que permaneceram no curso participaram das entrevistas.

Ao ponderar sobre o significado da aquisição de um diploma para graduandos em situações socioeconómicas menos privilegiadas esse pode servir como um instrumento de acesso à melhores condições no mercado de trabalho, bem como a cursos de especializações, mestrado e doutorado, e dessa forma a uma melhor qualidade de vida (LEMOS; NEVES; RODRIGUES, 20I3). Esses motivos acabaram superando as dificuldades encontradas durante a formação, como a falta de reconhecimento do curso perante a sociedade, atraso das disciplinas por falta de professores, desinteresse da instituição e dos professores e fatores pessoais que muitas vezes atrapalham o desempenho durante as aulas. 
Nas respostas dadas pelos estudantes que continuavam na graduação (Quadro I) no período desta pesquisa obtivemos uma visão geral dos motivos que os levaram a continuar cursando a LICA.

Quadro I: Respostas dos alunos que continuam matriculados no curso de Licenciatura em Ciências Agrárias (LICA), na Unidade Universitária da Universidade Estadual do Rio Grande do Sul - UERGS - em Vacaria, no ano de 2019 (n = número de respondentes).

\begin{tabular}{|c|c|c|c|}
\hline Perguntas & Respostas & Justificativas & $\mathbf{n}$ \\
\hline \multirow{4}{*}{ Já pensou em desistir? } & \multirow{3}{*}{ Sim } & $\begin{array}{l}\text { Falta de reconhecimento do curso nas escolas e } \\
\text { pela sociedade }\end{array}$ & 6 \\
\hline & & $\begin{array}{l}\text { Desinteresse por parte dos professores com o } \\
\text { curso e com os alunos }\end{array}$ & 4 \\
\hline & & Falta de incentivo & 3 \\
\hline & Não & Por agregar conhecimentos & 2 \\
\hline \multirow{2}{*}{ Motivos que levaram a continuar? } & \multicolumn{2}{|r|}{ Concluir uma graduação } & 4 \\
\hline & \multicolumn{2}{|r|}{ Exercer a profissão } & 4 \\
\hline \multirow{3}{*}{ O que poderia ser melhorado no curso? } & & Divulgação do curso & 8 \\
\hline & & Maior quantidade de aulas práticas & 4 \\
\hline & \multicolumn{2}{|c|}{ Melhor planejamento das aulas, por parte dos professores } & 3 \\
\hline \multirow{2}{*}{$\begin{array}{c}\text { A instituição forneceu todas as informações } \\
\text { necessárias sobre o curso quando você in- } \\
\text { gressou? }\end{array}$} & Não & $\begin{array}{c}\text { Informaram que poderia lecionar qualquer matéria } \\
\text { como biologia, química e física ou trabalhar no } \\
\text { meio agrário }\end{array}$ & 7 \\
\hline & Sim & Não justificou a resposta & I \\
\hline \multirow{4}{*}{ Você está satisfeito com o curso? } & \multirow[b]{2}{*}{ Não } & Falta de reconhecimento do curso & 6 \\
\hline & & $\begin{array}{l}\text { Falta de interesse por parte da instituição e profes- } \\
\text { sores }\end{array}$ & 4 \\
\hline & \multirow{2}{*}{ Sim } & Pratica o que aprendeu no trabalho & I \\
\hline & & Por ser um curso gratuito & I \\
\hline \multirow{4}{*}{$\begin{array}{l}\text { Você teve dúvidas se escolheria ou não esse } \\
\text { curso? }\end{array}$} & \multirow{3}{*}{ Não } & Curso gratuito & 5 \\
\hline & & Para agregar no currículo & 3 \\
\hline & & $\begin{array}{l}\text { Pela universidade estar na mesma cidade em que } \\
\text { residem }\end{array}$ & 2 \\
\hline & Sim & Dúvidas entre cursos & 2 \\
\hline \multirow{2}{*}{$\begin{array}{l}\text { Seus familiares e amigos aprovaram a escolha } \\
\text { deste curso? }\end{array}$} & Sim & Incentivaram e apoiaram & 5 \\
\hline & Não & Familiares e amigos não opinaram na escolha & 3 \\
\hline \multirow{6}{*}{ Você já fez algum outro curso? } & \multirow{5}{*}{ Sim } & Técnico em Agropecuária & I \\
\hline & & Técnico em Segurança do Trabalho & I \\
\hline & & Matemática e Fruticultura & I \\
\hline & & Ciência da Computação & I \\
\hline & & Curso de Empreendedorismo & 1 \\
\hline & \multicolumn{2}{|c|}{ Não realizaram outros cursos } & 3 \\
\hline \multirow{5}{*}{ Pretende fazer outros cursos? } & \multirow{4}{*}{ Sim } & Pós-graduação & 2 \\
\hline & & Bacharelado & 2 \\
\hline & & Especialização & 2 \\
\hline & & Mestrado & I \\
\hline & & Não pretende fazer outros cursos & I \\
\hline
\end{tabular}

Fonte: Autores (2020). 
Para você que continua no curso, quais motivos o levaram a continuar? Alguma vez já pensou em desistir? Por quê?

Seis entrevistados declararam ter pensado em desistir do curso devido ao não reconhecimento pelas escolas e pela sociedade: "o nosso curso não é reconhecido até o presente momento, por isso que eu pensei em desistir". Outros quatro devido à falta de incentivo e interesse por parte dos professores: "ver o desânimo dos professores que não querem acreditar no potencial dos alunos". Apenas dois entrevistados afirmaram que não pensaram em desistir da LICA, isso por já estarem trabalhando na área agrícola e, desta forma, conseguirem agregar conhecimento para a sua profissão. Porém, um deles mostrou desmotivação: "Mas cansa pelas aulas mal elaboradas e por ver a desistência dos colegas". Quando são criam muitas expectativas em relação a cursos e a instituição de ensino é comum se deparar com situações desagradáveis, sendo natural se sentir decepcionado, pois as expectativas impactam no nível de compromisso e de investimento dos estudantes, afetando a qualidade da adaptação acadêmica, o nível de aprendizagem, o desenvolvimento psicossocial e a persistência nas tarefas acadêmicas (OLIVEIRA, 20I6).

Os motivos que levaram a continuar na LICA foram o objetivo de concluir uma graduação, a gratuidade do curso e conseguir um diploma $(n=4)$ : "um curso gratuito é uma forma de conquistar uma graduação de nível superior". Outros quatro entrevistados consideraram ser importante conseguir exercer a profissão de docente: "quis continuar na esperança que vou conseguir exercer a profissão".

\section{O que poderia ser melhorado no curso?}

O ponto com maior destaque dado pelos entrevistados foi a necessidade de investimento na divulgação: "com mais divulgação do curso teria mais facilidade para ser inserido no mercado de trabalho". Conforme Santiago (20l6), ao escolher criar um curso de graduação, que acreditamos ser o melhor, muitas vezes não são analisadas as necessidades do mercado de trabalho, sua aceitabilidade, a valorização profissional e ambiente corporativo; fazendo com que os formandos encontrem dificuldades para conseguir uma posição.

A falta de vontade por parte dos professores em planejar melhor as aulas e oferecerem mais aulas práticas também foi apontado: "aulas com melhor planejamento pelos professores como eram nos dois primeiros semestres". Para Fonseca (2008) a falta de entusiasmo do professor, a dificuldade de tornar o conteúdo vivo e significativo faz o estudo se tornar cansativo e rotineiro, levando os educandos ao desinteresse.

\section{A instituição forneceu todas as informações necessárias sobre o curso quando você ingressou?}

Sete entrevistados indicaram que a instituição não forneceu todas as informações necessárias: "achei que eu iria sair daqui dando aula para as séries do fundamental, do nível médio até o nível técnico. Que poderia dar aula de biologia, física, química. Só que ao longo do curso entendi que não era bem assim”. Outro entrevistado afirmou: "não chegou a ser esclarecido, os professores não tinham conhecimento aonde os profissionais formados poderiam trabalhar, a própria Universidade não entendeu isso direito, não pesquisou e também não passou para o aluno".

\section{Você está satisfeito com o curso? Por quê?}

Seis entrevistados se declararam insatisfeitos com o curso por diversos motivos, entre eles a falta de reconhecimento do curso e a falta de interesse da instituição e dos professores: "o curso deixou a desejar, foram quatro anos e meio de um curso que não leva nem em Agronomia, porque não posso assinar como agrônomo, e nem para a parte da docência, já que as escolas e a CRE não reconhecem o curso". Dentre os que se declararam satisfeitos com o curso um deles afirmou que conseguiu aprender muito e aplicar no seu local de trabalho: "pessoalmente estou satisfeito, porque aprendi as áreas que eu precisava". Já o segundo estudante afirmou: "só tenho a agradecer à instituição e aos professores, apesar de não ter atingido todas as minhas expectativas. Entendo que a Uergs está muito relacionada com o governo como poder público". A esse respeito o fato de uma licenciatura ter sido desenvolvida por quase três anos com apenas um ou nenhum professor licenciado lotado na unidade pode ser considerado um fator de extrema relevância que comprometeu o andamento do curso e que não dependia da unidade para sua solução, mas sim do governo estadual, tendo a unidade procurado sanar a demanda por meio do auxílio de licenciados de outras unidades. 
No momento da escolha, você teve dúvidas se escolheria, ou não esse curso?

Seis entrevistados afirmaram que não tiveram dúvidas na hora da escolha devido a facilidade de acesso à universidade, a gratuidade do curso, a existência da Uergs na cidade de residência e por acrescentar valor aos seus currículos. Dois tiveram dúvidas mas fizeram a matrícula por ser na mesma cidade de residência e por seu currículo ser na área agrária. Outro estudante afirmou ter se matriculado exclusivamente pela área agrária do currículo, enfatizando ter mais interesse nessa área do que na licenciatura:

“Entrei principalmente pela área agrária. Eu queria agronomia, mas não estava ao meu alcance. Os professores falaram que poderíamos trabalhar na área agrária, tanto que um estágio foi na área agrária, mas no final do curso em diante foi levado mais para o lado da licenciatura, porque até então pensávamos que poderíamos trabalhar tanto na área agrária quanto na parte de licenciatura somente com a graduação."

\section{Seus familiares e/ou amigos aprovaram a escolha deste curso?}

Cinco estudantes tiveram o apoio de familiares e amigos, e para outros três os familiares e amigos não se manifestaram. Segundo o coordenador pedagógico Alexandre Barboza a família que se envolve e procura entender a universidade e o curso no qual seu filho está inserido terá mais condições e encontrará mais recursos para ajudá-lo nessa caminhada (BARBOZA, 20I8).

\section{Você já fez, ou pretende fazer, outro curso?}

Cinco entrevistados realizaram outros cursos; como Técnico em Agropecuária, Técnico em Segurança do Trabalho, Matemática, Fruticultura, Ciências da Computação e cursos básicos de Empreendedorismo. Os outros três não haviam realizado outros cursos. Sete pretendem continuar os estudos com pós-graduação e mestrado. Alguns pretendem continuar na área das agrárias: "pretendo fazer uma especialização na área de ciências agrárias", outros pretendem fazer outros cursos diferentes da área agrária: "pretendo cursar administração ou contabilidade". Há ainda aqueles que pretendem continuar na área da docência: "uma pós para complementar licenciatura" e um deles não pretende continuar com os estudos: "pretendo focar só nesse".

Cada entrevistado irá procurar a melhor forma de aproveitar o curso realizado. Aqueles que estão trabalhando no meio agrícola já estão aplicando os conhecimentos aprendidos durante a formação, outros pretendem fazer uma pós-graduação com a intenção de complementar o seu currículo seja na área agrária ou na docência.

\section{Alunos Evadidos}

A entrevista foi realizada com nove dos 32 alunos evadidos, o que representa $28 \%$ dos estudantes que evadiram. Durante as entrevistas percebeu-se que a desmotivação desfez as expectativas em relação ao curso, levando à evasão.

O sociólogo Jessé Souza, autor do livro Ralé Brasileira, aponta como um dos fatores da desmotivação dos alunos a própria instituição de ensino, a qual é chamada de má-fé institucional:

A crueldade da má-fé institucional está em garantir a permanência da ralé na escola, sem isso significar, contudo, sua inclusão efetiva no mundo escolar, pois sua condição social e a própria instituição impedem a construção de uma relação afetiva positiva com o conhecimento (SOUZA, 2009).

A chamada "ralé" para o autor seria constituída por pessoas humildes, com baixa condição financeira que não podem pagar por um ensino particular. Para o autor esses alunos estariam inseridos em sala de aula, mas não estariam efetivamente inclusos no processo interativo das instituições.

Durante a entrevista com os evadidos a palavra que mais foi repetida entre os entrevistados foi "falta", passando a imagem de que o curso de certa forma deixou muito a desejar. Outros motivos que mencionados foram problemas pessoais e falta de afinidade com a LICA, fazendo com que esse percentual de evasão se elevasse (Quadro 2). 
Quadro 2: Respostas dos alunos evadidos do curso de Licenciatura em Ciências Agrárias (LICA), na Unidade Universitária da Universidade Estadual do Rio Grande do Sul - UERGS - em Vacaria, que responderam a pesquisa em 2019 ( $\mathrm{n}=$ número de respondentes).

\begin{tabular}{|c|c|c|c|}
\hline Perguntas & Respostas & Justificativas & $\mathbf{n}$ \\
\hline \multirow{6}{*}{ Motivos que levaram a desistir do curso? } & \multicolumn{2}{|r|}{ Falta de reconhecimento do curso } & 4 \\
\hline & \multicolumn{2}{|r|}{ Falta de divulgação do curso } & 3 \\
\hline & \multicolumn{2}{|r|}{ Falta de afinidade com o curso } & 3 \\
\hline & \multicolumn{2}{|r|}{ Falta de interesse dos professores } & 3 \\
\hline & \multicolumn{2}{|r|}{ Problemas pessoais } & 2 \\
\hline & \multicolumn{2}{|r|}{ Falta de credibilidade do curso } & I \\
\hline \multirow{5}{*}{ O que poderia ser melhorado no curso? } & \multicolumn{2}{|r|}{ Ter mais divulgação do curso } & 6 \\
\hline & \multicolumn{2}{|r|}{ Deixar claro a área de atuação } & 5 \\
\hline & \multicolumn{2}{|r|}{ Ter aumentado a quantidade de aulas práticas } & 4 \\
\hline & \multicolumn{2}{|r|}{ Grade curricular do curso } & 3 \\
\hline & \multicolumn{2}{|r|}{ Colaboração dos professores } & 2 \\
\hline \multirow{2}{*}{$\begin{array}{l}\text { A instituição forneceu todas as informações ne- } \\
\text { cessárias sobre o curso quando você ingressou? }\end{array}$} & Não & $\begin{array}{l}\text { Passaram que poderíamos lecionar qualquer matéria como } \\
\text { biologia, química e física ou trabalhar no meio agrário }\end{array}$ & 6 \\
\hline & Sim & Forneceu as informações & 3 \\
\hline \multirow{3}{*}{ Porque você escolheu o curso que abandonou? } & \multicolumn{2}{|r|}{ Área da docência } & 5 \\
\hline & \multicolumn{2}{|r|}{ Área agrária } & 4 \\
\hline & \multicolumn{2}{|r|}{ Melhorar a situação financeira } & 3 \\
\hline \multirow{3}{*}{ Você teve dúvidas em escolher o curso? } & \multirow{2}{*}{ Não } & Área agrária & 4 \\
\hline & & Área da docência & 3 \\
\hline & Sim & Dúvidas entre cursos & 2 \\
\hline \multirow{2}{*}{$\begin{array}{l}\text { Seus familiares e amigos aprovaram a escolha } \\
\text { deste curso? }\end{array}$} & Sim & Incentivaram e apoiaram & 7 \\
\hline & Não & Familiares e amigos não opinaram sobre a escolha & 2 \\
\hline \multirow{5}{*}{ Você já fez algum outro curso? } & \multirow{4}{*}{ Sim } & Tecnologia em Educação Ambiental & I \\
\hline & & Técnico Agrícola & $\mathrm{I}$ \\
\hline & & Marketing & I \\
\hline & & Fruticultura & $\mathrm{I}$ \\
\hline & \multicolumn{2}{|r|}{ Não realizaram outros cursos } & 5 \\
\hline \multirow{5}{*}{ Estão cursando algum curso? } & & Agronomia & 3 \\
\hline & & Licenciatura em Ciências Biológicas & 2 \\
\hline & (IIII & Pedagogia & $\mathrm{I}$ \\
\hline & & Licenciatura em Educação Física & $\mathrm{I}$ \\
\hline & & Não estão cursando & 2 \\
\hline & & Pós-Graduação & 3 \\
\hline & & Mestrado & 2 \\
\hline 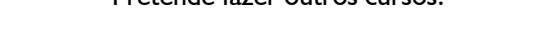 & Sim & Especialização & 2 \\
\hline & & Bacharelado & $\mathrm{I}$ \\
\hline & & Professores da instituição & 5 \\
\hline & Sim & Amigos & 2 \\
\hline $\begin{array}{l}\text { Antes de tomar a decisão de abandonar o curso, } \\
\text { yocê cheơu a conversar com alguém? }\end{array}$ & & Familiares & 2 \\
\hline & N $\tilde{n}^{-}$ & Família, amigos e professores não influenciam na decisão & 4 \\
\hline & & Professores ocupados & 3 \\
\hline & & Aproveitar matérias para outros cursos & 5 \\
\hline Estava satisfeito de alguma forma com o curso & Sim & Aulas práticas & 2 \\
\hline que abandonou? & & No primeiro ano do curso & 2 \\
\hline & & Não & 4 \\
\hline
\end{tabular}

Fonte: Autores (2019). 


\section{Quais foram os motivos que levaram você a desistir do curso?}

Alguns dos principais motivos declarados para a evasão teriam sido a falta de reconhecimento do curso $(n=4)$, falta de divulgação ou afinidade com curso e não identificação de interesse dos professores com o curso ( $n=3$ em cada categoria). Informações complementares sobre esse tema estão nos demais itens apresentados.

\section{O que poderia ser melhorado no curso?}

A maior parte das respostas esteve ligada com questões já destacadas pelos alunos que permaneceram na LICA, como a necessidade de maior divulgação do curso $(n=6)$ e clareza quanto a área de atuação dos licenciados $(n=5)$. Vejamos algumas opiniões: I) "a grade curricular deveria de ser elevada mais para o lado de licenciatura, ela está mais para um lado científico técnico do que para o lado de formar professores isso deveria ser corrigido"; 2 ) "a gente fica meio perdido não sabendo em que vai trabalhar"; 3 ) "enquanto eu estava no curso não tinha perspectiva aonde eu iria atuar". Dos entrevistados apenas dois atribuíram como pontos de melhoria o acompanhamento dos professores: I) "se mudasse a dinâmica de trabalho dos professores daria uma diferença enorme no curso"; e 2) "o curso em si é bom mas, qual aproveitamento que se pode ter se o curso não é reconhecido?".

\section{A instituição forneceu todas as informações necessárias sobre o curso quando você ingressou?}

Seis entrevistados responderam que a instituição não passou todas as informações necessárias, reforçando opiniões também apresentadas pelos graduandos que permaneceram no curso. Vejamos: I) "foi dito que nós poderíamos lecionar nas escolas na área de física, química, biologia, enfim, todas as matérias que tivesse durante o curso, ou poderíamos seguir no ramo agrário", e 2) "foi passado que poderíamos dar aula de diversas matérias e poderíamos trabalhar na parte agrária, no campo, por isso que a maioria de nós persistiu no curso, até perceber que não era bem assim". Somente três entrevistados disseram que foram passadas e esclarecidas todas as informações necessárias: "foi bem esclarecido o curso e a área que iria abranger".

Segundo a psicóloga e orientadora vocacional Maria Célia Lassance (em entrevista para o portal GauchaZH) para que os ingressantes no ensino superior se mantenham nas graduações para as quais foram inscritos é importante que a instituição passe todas as informações referentes ao curso escoIhido pelo estudante. "Em 35 anos de acompanhamento de estudantes, posso dizer que entre $70 \%$ e $80 \%$ dos que procuram auxílio optam por continuar no curso. A decepção geralmente vem da falta de informação antes de entrar na faculdade" (PSICÓLOGOS, 2013).

\section{Porque você escolheu o curso que abandonou?}

Cinco dos entrevistados escolheu o curso pelo interesse na área da docência, enquanto três indicaram a motivação pela busca por melhor salário: "escolhi porque queria ter uma ideia do ensino fundamental II e no médio e seguir para tentar melhorar o meu salário". Outros evadidos preferiram a LICA por ser mais próximo da área que gostariam de cursar: "na época escolhi porque estava mais próximo do que eu queria".

Muitas pessoas escolhem uma licenciatura pela carência de professores em praticamente todas as áreas do conhecimento abordadas nas escolas, aumentando as chances de ser contratado. Segundo os dados do Censo Escolar da educação básica de 2018, os Indicadores de Adequação da Formação Docente mostram que os piores resultados estão nos anos finais do ensino fundamental já que apenas $31,5 \%$ dos docentes possuem a formação adequada para ensinar a matéria (BRASIL, 20I8).

\section{No momento da escolha, você teve dúvidas se escolheria, ou não esse curso?}

Sete entrevistados afirmaram que não tiveram dúvidas na hora da escolha pelo curso: I) "não tive dúvidas porque queria mesmo ir para parte de licenciatura", 2) "não tive dúvidas porque o curso é gratuito", 3) "por ser uma combinação com agronomia consegui aproveitar muitas disciplinas". Dois relataram terem tido dúvidas, por terem passado em dois cursos: "tive dúvidas porque na época eu iria ingressar em letras, mas a Licenciatura em Ciências Agrárias não me daria gastos". Um dos estudantes mencionou que caso houvesse escolhido a outra licenciatura poderia já estar formado: "hoje penso que perdi tempo, porque se estivesse formada em outro curso eu estaria estruturalmente diferente hoje, talvez pudesse dar uma casa melhor para minha família”. 


\title{
Seus familiares e/ou amigos aprovaram a escolha deste curso?
}

A maioria dos entrevistados $(n=7)$ teve apoio de familiares e amigos na escolha do curso: I) "meus familiares aprovaram a escolha desse curso principalmente minha mãe que ama ciências", 2) "sim, a princípio não houve desaprovação".

\section{Você já fez, ou pretende fazer, outro curso?}

Quatro respondentes fizeram outros cursos: Tecnologia em Educação Ambiental, Fruticultura, Técnico Agrícola e Marketing; e cinco ingressaram direto do ensino médio. Sete já iniciaram outras graduações, sendo que quatro continuaram na área de docência por meio de Licenciaturas em Ciência Biológicas, Educação Física e Pedagogia e três estão cursando Agronomia. Entre os entrevistados apenas um não pensa em realizar outros cursos.

\section{Antes de tomar a decisão de abandonar o curso, você chegou a conversar com alguém?}

Quatro alunos não procuraram ninguém antes de sair da LICA. Um deles relatou a motivação para não procurar auxiliarem na sua decisão:

\begin{abstract}
"Não procurei ninguém, porque quando a gente iria procurar os professores estavam sempre preocupados com outra coisa, preocupados com a agronomia. Quando você tem a decisão de desistir de algo parte da gente, quando você toma essa decisão não vai ter professor e familiares que te faça mudar a tua opinião. Se você está desistindo é porque algo não estava mais dando certo."
\end{abstract}

Cinco conversaram com alguns professores. No caso dos estudantes que desistiram entre o $2^{\circ}$ e $4^{\circ}$ semestre os professores incentivaram a saída do curso: "conversei com um dos professores que me incentivou muito a migrar para o curso de Agronomia". No caso daqueles que desistiram entre $\circ 5^{\circ}$ e $7^{\circ}$ semestre os professores os incentivaram a ficar na LICA: "conversei com alguns professores e me aconselharam a continuar e pelo menos terminar, mas resolvi parar porque vi que o curso não estava indo para frente". Outro entrevistado relatou:

\footnotetext{
"Logo que se iniciou o curso de Agronomia na unidade, quando questionei um professor durante a sua aula, se posicionou afirmando que o curso de Agronomia não era para nós: "o curso foi aberto para os alunos que recém saíram do ensino médio e que possuem tempo disponível"."
}

Diante dessas duas realidades o posicionamento de alguns professores teria sido de incentivo para a troca de curso e de outros foi para a permanência no mesmo, não abrindo mão, entretanto, da responsabilidade pessoal pela decisão.

\section{Você estava satisfeito(a) com o Curso que abandonou?}

Cinco estavam, de certa forma, satisfeitos com o a LICA: I) "estava satisfeita até aonde fiz, porque aproveitei muitas matérias do curso.", 2) "sim, até chegar o curso de Agronomia depois não mais, acredito que esse seja o motivo de muitos terem desistido do curso, a desmotivação". Outro estudante relata: "sim, não era um curso ruim, algumas aulas valia a pena sair no frio para assistir, principalmente as aulas no laboratório eram muito bem feitas, $50 \%$ valeu do curso". Quatro desses estudantes não estavam satisfeitos, em especial por questões de validação do curso no mercado de trabalho: "não, porque quando eu fui pesquisar os contratos emergenciais para professores não tinha área de trabalho na área do curso".

\section{Professores e funcionários}

Muitas das motivações para a insatisfação dos alunos com o curso se deveram não a falta de qualidade das aulas, mas as próprias questões ligadas ao planejamento e divulgação da LICA. Nesse sentido, deve-se levar em conta que tão importante quanto mensurar a satisfação dos discentes com os cursos é mensurar o nível de motivação dos próprios docentes, tendo em vista serem eles a ponte de ligação entre a gestão e o alunado (SPLENDOR, 20I3). 
Durante as entrevistas muitos dos professores demonstram desmotivados e insatisfeitos com a abertura dessa licenciatura, visto que, segundo alguns deles, sua abertura serviu apenas para não deixar a unidade sem ofertar cursos durante o ano de 2015, não sendo um desejo da unidade. A entrevista foi realizada com nove profissionais da instituição e registramos diversos pontos de vista sobre a evasão. Podemos observar no Quadro 3 as respostas dos docentes e funcionários entrevistado.

Quadro 3: Respostas dos professores e funcionários que atuam junto ao curso de Licenciatura em Ciências Agrárias (LICA), na Unidade Universitária da Universidade Estadual do Rio Grande do Sul - UERGS - em Vacaria, que responderam a pesquisa em 2019 ( $n=$ número de respondentes).

\begin{tabular}{|c|c|c|c|}
\hline \multicolumn{4}{|c|}{ Professores e Funcionários } \\
\hline Perguntas & Respostas & Justificativas & $\mathbf{n}$ \\
\hline \multirow{14}{*}{$\begin{array}{l}\text { Ao que você atribui a alta evasão de alunos } \\
\text { durante o curso? }\end{array}$} & \multicolumn{2}{|r|}{ Por não saber o campo de atuação } & 4 \\
\hline & \multicolumn{2}{|r|}{ Não ter outra turma } & 4 \\
\hline & \multicolumn{2}{|r|}{ Falta de reconhecimento do curso } & 3 \\
\hline & \multicolumn{2}{|r|}{ Pela má coordenação da turma } & 2 \\
\hline & \multicolumn{2}{|r|}{ Falta de afinidade } & 2 \\
\hline & \multicolumn{2}{|r|}{ Falta de professores para as aulas } & I \\
\hline & \multicolumn{2}{|r|}{ Desestímulo } & 1 \\
\hline & \multicolumn{2}{|r|}{ Nome do curso, não adequado } & 1 \\
\hline & \multicolumn{2}{|r|}{ Falta de divulgação } & 1 \\
\hline & \multicolumn{2}{|r|}{ Falta de apoio para a turma } & I \\
\hline & \multicolumn{2}{|r|}{ Troca de curso } & I \\
\hline & \multicolumn{2}{|r|}{ Preguiça dos alunos } & 1 \\
\hline & \multicolumn{2}{|r|}{ Falta de planejamento por parte dos alunos } & 1 \\
\hline & \multicolumn{2}{|r|}{ Falta de interesse da instituição } & 1 \\
\hline \multirow{6}{*}{$\begin{array}{l}\text { Algo poderia ser feito para reduzir o número } \\
\text { elevado de alunos desistentes? }\end{array}$} & \multirow{5}{*}{ Sim } & Abrindo novas turmas do curso & 3 \\
\hline & & O coordenador & 2 \\
\hline & & Melhor atendimento dos professores com os alunos & 2 \\
\hline & & Alterar a grade curricular & I \\
\hline & & $\begin{array}{c}\text { Manter uma comunicação com a SMED, CRE e as escolas } \\
\text { sobre o curso }\end{array}$ & I \\
\hline & Não & Questões familiares do aluno & 1 \\
\hline \multirow{2}{*}{ Porque abriram o curso de LICA? } & \multicolumn{2}{|c|}{ Para servir de ponte, para trazer o curso de Agronomia } & \\
\hline & \multicolumn{2}{|r|}{ Por uma demanda do estado } & 3 \\
\hline \multirow{3}{*}{$\begin{array}{l}\text { Houve alguma demanda do município para o } \\
\text { curso de LICA ser aberto? }\end{array}$} & Não & O curso não era para ser aberto & 4 \\
\hline & Sim & Foi uma demanda do município e do estado & 2 \\
\hline & \multicolumn{2}{|r|}{ Não sei } & 3 \\
\hline \multirow{8}{*}{$\begin{array}{l}\text { Após aberto o curso de Agronomia, em sua } \\
\text { opinião, o curso de LICA foi de certa forma } \\
\text { "deixado de lado", já que a maioria dos pro- } \\
\text { fessores são agrônomos? }\end{array}$} & \multirow{4}{*}{ Sim } & Curso com maior interesse pelos professores & 4 \\
\hline & & O curso de Agronomia teve mais prioridade & 1 \\
\hline & & Curso clássico & I \\
\hline & & Priorizado o convênio com o IFRS & 1 \\
\hline & \multirow{4}{*}{ Não } & Os dois cursos são do mesmo campo das agrárias & 1 \\
\hline & & $\begin{array}{l}\text { Alta evasão provocou a desmotivação dos professores e } \\
\text { da instituição pelo curso }\end{array}$ & 1 \\
\hline & & A turma não tem motivação & I \\
\hline & & $\begin{array}{l}\text { Porque o curso de Licenciatura em Ciências Agrárias não } \\
\text { foi uma decisão da unidade e sim da reitoria }\end{array}$ & 1 \\
\hline
\end{tabular}

Fonte: Autores (2019). 
Ao que você atribui a alta evasão de alunos durante o curso?

Boa parte dos entrevistados atribuíram à alta evasão da LICA a motivos também mencionados pelos alunos, entre eles a falta de clareza quanto a área de atuação no mercado de trabalho $(n=4)$. Vajamos algumas opiniões: I) "por não entender aonde poderia atuar, visto que é uma licenciatura não é só a parte agrária", 2) "pelas poucas opções de concurso, por não dar muitas opções para esse profissional". Outro ponto apontado foi a falta de divulgação e reconhecimento da LICA fora da instituição (três respostas): I) "quando você tem um curso consolidado com atuação já reconhecida na sociedade tende a ter um menor número de evasão", 2) "o nome do curso foi um equívoco porque a habilitação é a mesma da Educação no Campo e não ter mudado o nome do curso também foi um equívoco". A não adaptação dos graduandos matriculados também foi mencionada ("em alguns casos teve alunos que saíram do curso para cursar outro"); a falta de professores durante a graduação ("a falta de professor durante o curso, isso desestimula o aluno por ele não ter aquela sequência lógica") e a falta de coordenação na turma: ("alta evasão do curso de Licenciatura em Ciências Agrárias se deve muito pela coordenadoria do curso ter deixado a desejar o curso na parte de licenciatura e sempre frisando a parte de Ciências Agrárias". A falta de planejamento dos discentes também foi mencionada: "a culpa é dos alunos por não terem um planejamento, uma proposta, uma estratégia. Todas essas coisas são fundamentais, para conseguir e conquistar alguma coisa na vida é claro que tudo exige sacrifícios".

\section{Em sua opinião algo poderia ter sido feito para reduzir o número elevado de alunos que desistiram do curso?}

Para três dos entrevistados o que poderia reduzir a evasão seria a abertura de novas turmas: "sim ter aberto outras turmas do curso, com certeza daria mais motivação para alguns alunos continuar estudando, e o curso teria mais visão". Para dois dos entrevistados o coordenador do curso deveria ter informado a CRE sobre a abertura do mesmo, passando informações para que essa licenciatura tivesse o reconhecimento necessário nas escolas.

\footnotetext{
"O coordenador deveria ter informado a CRE, como seria o curso, qual perfil do egresso, tudo deveria ser informado para se ter possibilidades e para que aquele aluno do curso possa utilizar essas possibilidades para conseguir ter experiência depois do curso e consiga ser inserido no mercado de trabalho."

"Sim, deveríamos ter ido à SMED, na CRE conversado com as pessoas para ver qual a receptividade que vocês teriam, principalmente para os estágios. Em uma das reuniões na CRE eles não souberam nos informar que disciplinas vocês poderiam dar aula. Não houve tempo e discussão para amadurecer de como seria essa inserção, para informar para todos os alunos desde quando chegaram à Uergs, para que não houvesse abandono do curso."
}

Para outros dois dos entrevistados uma atenção maior dos professores para com os estudantes, poderia ter reduzido a evasão. Um deles relatou: "sim, todos os professores da unidade deveriam de ter acompanhado melhor os alunos, mostrando alternativas e caminhos de trabalho, assim muitos não teriam desistido do curso, isso passaria mais segurança para os alunos". Para um dos entrevistados o curso deveria ter apenas um direcionamento ou para licenciatura ou para ciências: "definindo o curso para licenciatura ou para ciências agrárias, porque desta forma o curso fica no meio não sendo o suficiente para a licenciatura e nem para as ciências agrárias".

\section{Porque abriram o curso de Licenciatura em Ciências Agrárias? Foi uma demanda do município?}

Seis entrevistados afirmaram que a LICA, serviu apenas como uma ponte para trazer o Bacharelado em Agronomia para a unidade. Um dos entrevistados afirma: "Não era para termos o curso de Licenciatura em Ciências Agrárias era para ser aberto o curso de Agronomia"; segundo outro entrevistado: "o curso foi um tapa furo, isso confirma porque o curso não abriu em mais nenhuma outra localidade, apenas aqui em Vacaria e turma única". Três entrevistados não sabiam se teve algum tipo de demanda do município para a abertura dessa licenciatura: "não sei se teve alguma demanda do município, eu pelo menos não participei de 
nenhuma conversa que envolvesse o município era uma demanda mais geral vinda do estado e aproveitando os professores da área das agrárias". Outros dois entrevistados afirmaram que teve uma demanda. Um deles afirmou que a demanda era do município e do estado: "sim foi uma demanda do município e do Estado" e o outro afirmou ter uma demanda, mas não especificou se era do estado ou do município: "sim eu soube que tinha uma demanda na área de educação".

\section{Após aberto o curso de Agronomia, em sua opinião, o curso de Licenciatura em Ciências Agrárias foi de certa forma “deixado de lado", já que a maioria dos professores são agrônomos?}

Cinco dos entrevistados afirmaram de muitas maneiras que a LICA foi de certa forma deixada de lado, em especial pela maioria dos professores da unidade serem agrônomos: "Sim foi deixado de lado, priorizando o convênio com o IFRS e com ênfase em Agronomia...”. Outros relatos dos entrevistados:

"Certamente o curso de agronomia ganhou prioridade, teve muito mais demanda, teve um interesse bem mais forte por ser um curso clássico, certamente tanto a demanda quanto o interesse dos professores foi maior."

"Não deveria, mas foi, o professor acabou se desmotivando ao ver a evasão dos alunos, mas aquela coisa que te digo com muita clareza, o curso foi apenas uma forma [...] para que tivéssemos pelo menos algum curso durante esse tempo na qual Agronomia ainda não tinha sido estabelecida na unidade."

"Abertura do curso de Licenciatura em Ciências Agrárias na unidade de Vacaria foi apenas uma ponte para Agronomia. Só foi aberto curso para não deixar vazio por um ano sem ofertar o curso. Nunca foi um desejo pelos professores, somente uma ponte."

Os outros quatro entrevistados acreditam, que a LICA, não foi "deixada de lado", após aberto Bacharelado em Agronomia: "não é deixado de lado acredito que a turma de vocês não é motivada. Não é uma questão de agronomia ou de licenciatura estamos formando pessoas e em diferentes condições". Outros relatos:

"Pela parte dos professores não, tanto Agronomia quanto Licenciatura em Ciências Agrárias são do mesmo campo das agrárias, não vejo por isso ser um motivo de ter sido deixado de lado. $O$ que eu vejo, que ajudou a serem deixados de lado, foi por ter pessoas contra o curso, porque achava que o curso de Agronomia tem mais futuro que o curso de Licenciatura em Ciências Agrárias na ideia de apoiar mais os alunos de Agronomia, deixaram de lado os alunos de licenciatura em ciências agrárias."

"Acredito que não é pelo fato dos professores serem agrônomos que deixaram o curso de Licenciatura em Ciências Agrárias de lado, acredito que pelo curso, pela alta evasão que se teve, desmotivou a instituição para abertura de novos cursos. Acredito que teve uma competição entre os alunos que procuram mais Agronomia do que o Curso de Licenciatura em Ciências Agrárias, pela falta de reconhecimento do curso no mercado. $O$ curso de agronomia é centenário no qual o mercado de trabalho reconhece muito mais do que um Licenciado em Ciências Agrárias.”

"Acredito que não foi por ser aberto o curso de Agronomia. Acredito que foi pela forma de como foi feita as coisas. Porque desde 2013 o desejo da unidade era trazer o curso de Agronomia, porque era o que todos os professores tinham afinidade por serem a maioria agrônomos.“

A forma como o curso foi criado afetou diretamente todos os envolvidos. Segundo os relatos os professores realizaram um planejamento de uma graduação que a maioria não queria, com o agravante de terem que fazê-lo às pressas para atender a uma demanda, sendo esse um dos motivos pelos quais o curso teria deixado muito a desejar sob a ótica dos estudantes. A instituição também saiu perdendo, segundo um dos 
alunos evadidos "por ofertar um curso mal planejado e isso de certa forma 'queima' a imagem da Uergs". Os estudantes que continuaram nessa graduação teriam continuado a acreditar de alguma maneira que sua formação poderia ser útil em suas vidas, seja na parte agrária ou na docência, uma vez que a grande maioria pretende realizar outras formações para enriquecer os seus currículos.

\section{Considerações Finais}

Mesmo que não seja do escopo das entrevistas chegar a uma verdade única, a discussão com os diferentes atores do curso de LICA-Uergs permitiu a identificação de fatores que podem explicar a evasão nesse curso. A regularidade com que se evocaram motivos de ordem prática para a evasão, como o não reconhecimento do curso e a falta de clareza quanto às possibilidades da atuação no mercado de trabalho, estando esses elementos presentes no discurso da maior parte dos entrevistados. Tanto alunos quanto docentes apresentaram a falta de oportunidade no mercado de trabalho como grande motivo para evasão.

O sentimento de abandono durante o curso relatado pelos estudantes, por sua vez, é complementado pelo relato dos professores ao declararem que a LICA serviu apenas como "uma ponte" ou "tapa furo" para trazer um bacharelado para a unidade, garantindo que a mesma não ficasse sem oferta de cursos durante um ano $(n=6)$. Se destacando diante disso os depoimentos dos alunos de que o aparente descaso com o curso acaba por desvalorizar o nome da instituição, por ofertarem uma graduação sem planejamento adequado quanto ao campo de atuação pós-formatura. Esse sentimento de insatisfação dos alunos, porém, pode ser relativizado, tendo em vista que a chegada do curso de Agronomia teria significado um grande aumento na carga horária dos professores e consequente redução do tempo disponível para o atendimento de cada disciplina. Isso tudo reforça ainda mais os dados fornecidos pelos Censos da Educação Superior que apontam a desvalorização das licenciaturas em favor dos bacharelados (BRASIL, 2017).

Chama especial atenção que, apesar da alta evasão, não registramos relatos no sentido de desmerecimento da importância da LICA ou mesmo das licenciaturas. Sendo verificado até mesmo certo nível de satisfação com parte do curso pelos evadidos. Isso pode ser um indicativo de que os problemas podem ter sido fortemente influenciados mais pelas questões de organização e planejamento, do que propriamente por má formação de professores.

Por fim, se constata que um planejamento para a abertura de novos cursos é indispensável. É preciso contar com uma clara e correta delimitação do campo de trabalho dos graduados e o engajamento de todos os envolvidos, sob pena de se entregar ao mercado de trabalho profissionais bem formados para um nicho específico, porém, sem o devido reconhecimento e articulação que permita o ingresso desses neste mercado. No decorrer do curso os estudantes podem identificar estas dificuldades e buscar outros cursos que lhes ofereçam o reconhecimento junto a sociedade e o mercado de trabalho.

\section{Referências}

ASSIS, C. F. Estudo dos fatores que influenciam a evasão dos alunos nos Cursos Superiores de Tecnologia de uma Instituição de Ensino Superior Privada, 2013. Dissertação de Mestrado, Faculdade Pedro Leopoldo, Pedro Leopoldo, 2013.

BARBOZA, A. A. O vestibular e a importância da família na aprovação do aluno. 2018. Disponível em: https:// www.em.com.br/app/noticia/especiais/educacao/enem/2018/08/02/noticia-especial-enem,977496/o-vestibular-e-a-importancia-da-familia-na-aprovacao-do-aluno.shtml. Acesso em: 28 set. 2019.

BRASIL. Lei de Diretrizes e Bases da Educação Nacional. Lei 9394, Brasília, 20 de dez. 1996.

BRASIL. Altos índices de desistência na graduação revelam fragilidade do ensino médio, avalia ministro, 2018. Disponível em: http://portal.mec.gov.br/ultimas-noticias/2 /2-educacao-superior-16906 /0854/40 III-altos-indices-de-evasao-na-graduacao-revelam-fragilidade-do-ensino-medio-avalia-ministro. Acesso em: 28 set. 2019.

BRASIL. Censo da Educação Superior Notas Estatísticas 2017. Brasília: INEP, 2017.

BRASIL. Censo Escolar 2017. Brasília: Ministério da Educação, 2018.

BRASIL. Cadastro Nacional de Cursos e Instituições de Educação Superior Cadastro e-MEC, 2019. Disponível no site: https://emec.mec.gov.br/. Acesso em: 26 jul. 2018. 
BRASIL. Panorama da educação do campo. Brasília: INEP, 2007.

BORGES, M. F. N. História de Vacaria: evolução urbana e formação dos bairros. Caxias do Sul: EDUCS, 200 I.

DAVOK, D. F; BERNARD, R. P. Avaliação dos índices de evasão nos cursos de graduação da Universidade do Estado de Santa Catarina - UDESC. Avaliação (Campinas), Sorocaba , v. 2 I, n. 2, p. 503-522, 2016.

FONSECA, T. M. Ensinar Aprender: Pensando a prática pedagógica. Ponta Grossa: Secretaria de Estado da Educação Superintendência da Educação Programa de Desenvolvimento Educacional - PDE, 2008.

BRITTO JÚNIOR Á. F.; FERES N. A utilização da técnica da entrevista em trabalhos científicos. Evidência, v. 7, n. 7, p. 237-250, 2011.

LEMOS, A. H.; NEVES, D. R.; RODRIGUES, P. R. F. Inserção de Alunos Bolsistas no Mercado de Trabalho: qual o valor do diploma universitário? Revista Pensamento Contemporâneo em Administração, Niterói, v. 7, n. 4, pp. 24-4I, 2013.

LOBO, M. B. Panorama da Evasão no Ensino Superior Brasileiro: Aspectos gerais das causas e soluções In. HORTA, C. E. R. (org). Evasão no ensino superior brasileiro. Brasília: ABMES, 2012.

MARCONI, M. D.; LAKOTOS, E. M. Fundamentos de Metodologia Científica. São Paulo: Atlas, 2017.

MATTOS, P. L. A entrevista não-estruturada como forma de conversação: razões e sugestões para sua análise. Revista de Administração Pública, Rio de Janeiro, v. 39, n.5, p. 823-846, 2005.

MEC (MINISTÉRIO DA EDUCAÇÃO). Altos índices de desistência na graduação revelam fragilidade do ensino médio, avalia ministro. 2016. Disponível em: http://portal.mec.gov.br/ultimas-noticias/2I2-educacao-superior- I 6906 I 0854/40 I I I-altos-indices-de-evasao-na-graduacao-revelam-fragilidade-do-ensino-medio-avalia-ministro. Acessado em: 19 set. 2019.

MOLINA, G. S. Desenvolvimento Sustentável na Região de Vacaria, In. Anais do II Seminário Internacional sobre Desenvolvimento Regional. Santa Cruz do Sul: UNISC, 2004. p. I- 19

MORAES, M. A. A formação de licenciados em Ciências Agrícolas/Agrárias: o conhecimento e suas conexões. Educação. Santa Maria, v. 39, n. 3, p. 64l-652, 2014.

OLIVEIRA, C. T. Expectativas de universitários sobre a universidade: sugestões para facilitar a adaptação acadêmica. Revista Brasileira de Orientação Profissional, Porto Alegre, v. 17, n. I, p. 43-53, 2016.

PRONACAMPO. Diretoria de Políticas de Educação do Campo, Indígena e Relações Étnico-racial. 20I2. Disponível em: http://pronacampo.mec.gov.br/images/pdf/ind_campo_indigena_e_quilombola.pdf. Acesso em: 28 set. 2019.

PSICÓLOGOS dão dicas para quem pensa ter entrado no curso errado. Portal GaúchaZH, 20I3. Disponível em: https://gauchazh.clicrbs.com.br/educacao-e-emprego/vestibular/noticia/2013/I2/psicologos-dao-dicas-para-quem-pensa-ter-entrado-no-curso-errado-436I22I.html. Acesso em: 28 set. 2019.

RIO GRANDE DO SUL. Lei n I I.646, de 10 de Julho de 200I. Autoriza o Poder Executivo a criar a Universidade Estadual do Rio Grande do Sul - UERGS e dá outras providências. Diário Oficial do Estado do Rio Grande do Sul. Porto Alegre, 200I.

ROTTA, M. ; ONOFRE, S. B. Perfil da educação do campo: na escola do São Francisco do Bandeira no Município de Dois Vizinhos- PR. Educação, Porto Alegre, v. 33, n. I, p. 75-84, jan./abr. 2010.

SANTIAGO, P. E. Ensino Superior E Mercado De Trabalho: a dificuldade dos profissionais do ensino superior para entrar no mercado de trabalho. Revista PLUS FRJ: Revista Multidisciplinar em Educação e Saúde da Faculdade Regional Jaguaribana, p. 43-8, n. I, 2016.

SEMESP. Mapa do Ensino Superior no Brasil. São Paulo: SEMESP, 2019.

SILVA, F. L.;MUZARDO, F. T. Gestão Da Sala De Aula: Contribuições Para A Construção De Um Conceito. Trilhas Pedagógicas, Pirassununga, v. 7, n. 7, p. 263-278, 2017.

SILVA, L. E. Um Olhar Sobre A Escola Como Espaço De Emancipação, 20I0. Dissertação de Mestrado, Universidade Regional Do Noroeste Do Estado Do Rio Grande Do Sul, UNIJUI, ljuí, 2010.

SILVA J. R.; ALMEIDA C. D.; GUINDANI J. F. Pesquisa documental: Pistas Teóricas e Metodológicas. Revista Brasileira de História \& Ciências Sociais. Rio Grande, Ano. I n. I, 2009.

SOUZA, J. Ralé Brasileira Quem é e como vive. Belo Horizonte: UFMG, 2009.

Pegoraro \& Braunstein | Rev. Elet. Cient. da UERGS (2020) v. 6, n. 01, p. 92-I08 
SPLENDOR, E. F. Evasão Escolar: o motivar, a família e a importância do Ensino Médio. Curitiba: SEED, 2013.

TAVARES, C. A.. A formação de professores agrícolas na Universidade Federal Rural de Pernambuco: Histórico, realidade e perspectivas. Anais da Academia Pernambucana de Ciência Agronômica, Recife, v. 2, p. 32-4I, 2005.

UERGS. Curso de Licenciatura em Ciências Agrárias: Objetivo do curso. 2015a. Disponível em: https://uergs.edu. br/ciencias-agrarias-licenciatura. Acesso em: 28 set. 2019.

UERGS, Edital No 01/2015 Processo Seletivo Uergs para provimento das vagas remanescentes do processo seletivo Sisu 20 I5/0 I. 2015b. Disponível em: https://www.uergs.edu.br/upload/arquivos/201710/I I I 10049-edital-n-I-processo-seletivo-sisu-2015-I.pdf. Acesso em: 28 set. 2019.

UERGS. Mec divulga aprovados em primeira chamada. 2015c. Disponível em https://www.uergs.edu.br/mec-divulga-aprovados-em-primeira-chamada. Acesso em: 28 set. 2019.

UERGS. Informações institucionais. 2018. Disponível em https://uergs-admin.rs.gov.br/upload/arquivos/201809/ 12162803-dados-institucionais-2018-I-site.pdf. Acesso em: 20 nov. 2019.

VANDRAMINI, C. Qual o futuro das escolas do campo?. Educação em Revista. Belo Horizonte, v.3I, n. 3, p. 49-69, 2015. 